\title{
Homossexuatidade,
}

\section{educação física e esporte: \\ primeiras aproximações}

\author{
Carlos Fernando Ferreira da Cunha Júnior* e Victor Andrade de Melo**
}

Este estudo objetiva indicar possíveis preconceitos e discriminações para com homossexuais masculinos no âmbito da Educação Ffsica/esporte. Para alcance do objetivo foi realizada uma revisão da literatura e uma análise aua-litativa de dez entrevistas. As constatações básicas foram: a) existe preconceito $e$ discriminação para com homossexuais; b) Educação Física escolar e professor foram apontados como responsáveis pelo afastamento dos homossexuais das atividades físicas/esportivas fora da escola; c) os professores contribuem com a perpetuação do preconceito e da discriminação; d) os homossexuais têm poucos espaços para a prática de atividades físicas/esportivas. Conclui indicando que tais questões devem constituir-se um desafio para os professores de Educação Física.

Nas últimas décadas, têm-se observado significativas alterações na organização da sociedade. Alguns autores inclusive têm defendido, a partir da constatação de tais mudanças, que o modelo da sociedade moderna ruiu e que estamos em plena transição para uma era pós-moderna (Derrida, 1967; Deleuze, Guattari, 1972; Lyotard, 1979).

Segundo Sérgio Paulo Rouanet (1987), os pensadores advogados do paradigma pósmoderno têm centrado suas críticas e análises na modernidade social (abrangendo a econo- mia e o Estado) e na cultural (abrangendo o saber, a moral e arte), sendo loquazes no argumento de renovação das formas de política realizadas na era pós-moderna.

\footnotetext{
Enquanto a política moderna tinha como palco o Estado e visava à conquista ou à manutenção do poder estatal, a política pós-moderna tem como palco a sociedade civil e visa à conquista de objetivos grupais ou segmentares. Os sujeitos da nova política não são mais cidadãos, mas grupos, e seus fins não são mais universais, visando ao interesse geral, mas micrológicos. (ibid., p.237)
}

A questão é extremamente polêmica e o próprio Rouanet (id.) defende que tal fato não representa ruptura com a modernidade, pois a emergência dos novos movimentos sociais significa muito mais um enriquecimento do campo político do que a superação da política moderna por uma nova política pós-moderna, segmentar e micrológica.

Críticas e defesas da pós-modernidade à parte, fato é que alguns movimentos sociais, as chamadas 'minorias', representam hodiernamente um papel importante na organização da sociedade. O presente estudo focaliza um destes grupos, os homossexuais, buscando identificar suas vivências na Educação Física e no esporte. Nos últimos anos, movimentos surgiram no intuito de combater o preconceito e a discriminação social e repensar as questões ligadas à homossexualidade. Tais discussões tornaram o assunto significativamente visível e têm contribuído na gradual redução do estigma social. A despeito disso, a Educa- 
ção Física brasileira parece estar desconhecendo a importância e profundidade dessa problemática. Assim, objetivamente, procuramos identificar manifestações de preconceitos e discriminações para com homossexuais masculinos (gays) ${ }^{l}$, identificados nos campos de atuação do professor de Educação Física ${ }^{2}$.

Procuramos com a realização deste trabalho: apontar novos caminhos de pesquisa para o tema, já que a literatura brasileira é escassa ou quase inexistente; alertar os professores da área a respeito da problemática levantada; e, finalmente, contribuir para alertar acerca da necessidade de que as atividades físicas/esportivas não estejam restritas a determinados segmentos da população. Para alcance do objetivo foi realizada uma revisão da literatura sobre o tema em questão e, fundamentalmente, uma análise qualitativa de conteúdo de dez entrevistas semi-estruturadas com homossexuais masculinos ${ }^{3}$.

\section{HOMOSSEXUALIDADE: DISCURSOS}

Cremos ser necessário inicialmente abordar alguns aspectos da homossexualidade, não com o intuito de discutir extenuadamente o assunto, mas buscando contextualizálo historicamente e conceituá-lo minimamente, objetivando compreender melhor como o preconceito e a discriminação ${ }^{4}$ para com os homossexuais vêm-se estabelecendo. Assim, esperamos também apontar um possível papel do professor de Educação Física neste processo.

Percebemos que as conceituações em torno da homossexualidade se apresentam bastante díspares. Consideramos, então, em nosso esforço de definição, exatamente essa inexatidão e a heterogeneidade da homossexualidade, assumindo-a como variações sobre um tema central: indivíduos do mesmo sexo que estabelecem relações sexuais e afetivas. Dessa forma, pretendíamos aproveitar a riqueza de situações que se apresentariam. Além disso, nosso entendimento básico é que a homossexualidade só pode ser plenamente compreendida a partir do contexto cultural em que se insere. Em culturas diferenciadas, a homossexualidade assume valores e significados diferentes. Obviamente, a partir disso, as mani- festações de preconceito e discriminação também o são.

Embora conscientes dessa diversidade cultural, que impede que consideremos de forma similar a homossexualidade numa tribo indígena, na Grécia Antiga e hodiemamente no eixo Rio de Janeiro-São Paulo, ao buscarmos entender como historicamente se tem construído os discursos de preconceito e discriminação, privilegiamos a compreensão generalizada daqueles construídos na sociedade brasileira. Dessa forma, estaríamos mais próximos de entender e refletir sobre as contemporâneas manifestações de preconceito e discriminação no contexto de nossos entrevistados, todos do Rio de Janeiro.

Enfim, a compreensão básica que permeia o estudo é de que não existem verdades absolutas estabelecidas acerca da homossexualidade, que não pode deixar de ser considerada, tanto suas idéias quanto as práticas ao ser redor, como produções historicamente situadas, social e culturalmente estabelecidas. Essa compreensão é muito importante para o intuito deste estudo, pois retira as discussões sobre a homossexualidade do campo estrito da religião, da psicologia e/ou da medicina, situando-as no campo mais amplo da cultura, onde encontramos inclusive as atividades físicas/ esportivas. Ao entendermos as grande linhas de discurso de preconceito e discriminação no decorrer do tempo, podemos traçar paralelos com a situação brasileira contemporânea, encontrando apontamentos diretamente ligados às atividades físicas/esportivas.

Várias são as categorias que surgiram na tentativa de "explicar" a homossexualidade, ligando-a a questões familiares, fatores genéticos, desordens religiosas e morais, entre outras, todas plenamente possíveis de serem consideradas como produções ideológicas. Por trás dessas categorias é possível identificar uma lógica, marcantes linhas de discurso. Um primeiro grande discurso observável no Brasil foi estabelecido pela ótica religiosa, a partir do papel central de "fiscalização" da Igreja Católica. As relações homossexuais eram consideradas "pecado de sodomia", crime passível de condenação à morte.

O discurso religioso foi marcante e ainda hoje, mesmo entre os setores mais pro- 
gressistas da maioria das religiões, continuam a existir concepções de que a homossexualidade seria um grave pecado. Mas é a partir aproximadamente da metade do século XIX que um discurso ainda mais influente, até mesmo devido à sua "consistência científica", começa a se tornar observável: o da preocupação médica para com a homossexualidade. Essa preocupação está ligada ao contexto de idéias higienistas acerca da "saúde" ${ }^{15}$ da nação, onde o controle da sexualidade tinha ligação direta à "saúde" da família, considerada estratégica. Com os médicos, a homossexualidade passa gradualmente de "pecado" para "doença" (Fry, MacRae, 1991).

Várias foram as propostas e os tratamentos desenvolvidos para "curar" homossexuais, encarados como nunca a partir da ótica biológica. Nessa gradual ascensão do discurso médico, sem que se possa delinear exatamente, os discursos da psicologia ganham relevância. Primeiro porque se aceitava a possibilidade de um defeito psicopatológico, além dos possíveis problemas endógenos, mas fundamentalmente devido à ascensão e influência da psicanálise freudiana. Para Freud, a heterossexualidade era a única condição sexual sadia e a procriação a finalidade máxima dessa relação. Obviamente, a homossexualidade estava excluída, sendo considerada como uma condição quase incurável. Talvez não exatamente uma doença, mas com certeza um grave defeito, fonte de infelicidade (ibid.)

É provável que a Educação Física tenha participado diretamente dessas "preocupações" para evitar o "surgimento" de homossexuais. Não podemos esquecer que a educação física esteve diretamente imersa em preocupações higienistas (Soares, 1991). E se estava diretamente vinculada ao impedimento do surgimento de "doenças" e à manutenção da ordem "moral", de alguma forma deve ter participado desses esforços de "cura" e de "prevenção". Isto é claramente identificável, por exemplo, na Teoria da transfiguração, uma teoria para o jogo, traçada a partir de uma visão evolucionista, de Inezil Penna Marinho. O autor afirma que:

$\mathrm{O}$ instinto da transfiguração poderá manifestar-se algumas vezes de forma alarmante, culminando com a transfiguração sexual,(...) fundamentalmente psíquica. Para evitar que o instinto da transfiguração nas suas manifesta- ções mais intensas e negativas, possa eclodir (...) trazendo conseqüências às vezes desastrosas, imperioso se torna propiciar à criança múltiplas oportunidades que funcionam como verdadeira válvula de segurança. (Marinho, 1953, p.43)

Esses discursos tiveram um papel central no estabelecimento dos preconceitos para com os homossexuais, considerados por muitos, ainda hoje, pecadores, doentes, na melhor das hipóteses infelizes. No entanto, movimentos de afirmação dos homossexuais foram organizados pronunciadamente a partir da década de 70, em busca de seu reconhecimento e de seus direitos, combatendo os preconceitos e as discriminações, lutando para abolir da sociedade estas compreensões distorcidas. A questão homossexual hoje ganha progressivamente relevância e ocupa espaços importantes. Muitas conquistas são observáveis, embora o preconceito e a discriminação estejam longe de ser exterminados.

Como será, então, que a Educação Física, que sempre privilegiou e se destinou a indivíduos "saudáveis", tem visto atualmente essa questão? Como se tem estabelecido dentro de nossa área preocupações quanto às possíveis barreiras que têm impedido o acesso de homossexuais a atividades físicas/esportivas?

EDUCAÇÃO FÍSICA, ESPORTES E HOMOSSEXUALIDADE: TEORIAS E VIVÊNCIAS

A revisão da literatura nacional não revelou nenhum estudo recente envolvendo homossexuais, Educação Física e/ou esporte. $\mathrm{Na}$ literatura internacional, embora também ainda não seja um assunto fartamente discutido, já é possível encontrar um número maior de reflexões e pesquisas, publicadas em periódicos especializados e/ou apresentados em eventos científicos ${ }^{6}$. Estes estudos têm em comum o fato de se originarem nas discussões das relações de gênero e por utilizarem fundamentalmente a homofobia e o heterossexismo como conceitos centrais de análise. Homofobia é entendida como: $O$ medo de sentimentos de amor por indivíduos do próprio sexo e por conseguinte o ódio desses sentimentos em outras pessoas (Lorde, 1984, p.45). Já heterossexismo é definido como 
a visão que a heterossexualidade é a norma para todas as relações sociais/sexuais...a institucionalização da heterossexualidade em todos aspectos da sociedade - incluindo a discriminação legal e social contra homossexuais e a negação dos direitos homossexuais enquanto um interesse político. (Moraga apud Lenskyj, op.cit., p.62)

Na realidade social, esses conceitos são perpetuados basicamente pelas instituições sociais, entre elas os sistemas educacionais, escolares e não-escolares, e, logo, também pelo profissional que ocupa o papel de professor, técnico, recreador etc. De fato, estudos mostram que não têm sido incomum manifestações de discriminação contra homossexuais na escola, no clube, nas academias de ginástica e no que os autores internacionais denominam recreação comunitária. Essa discriminação aparece de várias formas, desde agressões e espancamentos até injúrias e ofensas verbais, observáveis na forma de apelidos desmerecedores e estereotipados, ligados ao modo de ser, de se vestir e de agir dos homossexuais, considerados inevitavelmente como indivíduos fracos, "cheios de frescura", incapazes de praticar uma atividade física/esportiva, a não ser que. esta seja considerada uma atividade "feminina", como a dança. Dois dos entrevista$\operatorname{dos}^{7}$ deixam isso bem claro ao declarar que desde sua infância:

...já tinha discriminação, já tinha preconceito, já tinha o apelido, já tinha o estereótipo. "A rosinha!", "O viadinho!", "Ele é efeminado!" (...) comumente a gente se cala. A gente fica calado, a gente tem medo que as outras pessoas até ouçam você falar, porque elas vão... te encarnar (...) Você vai ser encarnado, vai ser chacoteado. (Entrevista 1)

Tinha medo. Medo de ser agredido, eu sabia que ia sofrer o preconceito. $\mathrm{O}$ maior medo era de ser agredido pelas pessoas. (Entrevista 2)

É interessante observar que alguns dos estereótipos acerca dos homossexuais foram descaracterizados a partir das entrevistas. Elas, por exemplo, mostraram claramente que, nas brincadeiras realizadas durante a infância e adolescência nos grupos da rua e da escola, poucos eram os homossexuais que gostavam de atividades "típicas das meninas", tais como "brincar de boneca" e de "comidinha". Por trás da não participação em atividades "típicas dos meninos" parece existir uma clara manifestação de preconceito e discriminação com aqueles que não apresentam um comportamento "modelar" masculino ${ }^{8}$, mesmo se eles apresentassem boa habilidade em alguma atividade.

...eu era o máximo no pingue-pongue. Mas eu era o máximo entre aspas, eu era o máximo para mim, para as pessoas não, por causa da sexualidade. Quer dizer, "Viado! Esse viado jogando aqui?" ...o domínio da mesa era dos meninos, o domínio é dos meninos. (Entrevista 1)

Enfim, o estereótipo acerca das brincadeiras não se justifica e o que se apresenta é um quadro muito mais complexo. Não é o homossexual que não gosta de praticar as atividades, mas existem uma série de fatores que o impede, o afasta das atividades.

O professor de Educação Física contribui muitas vezes no estabelecimento do preconceito e da discriminação, reforçando os estereótipos existentes através de seu discurso $^{9}$ ou até mesmo impedindo homossexuais de freqüentar suas atividades. Existem também aqueles professores que, embora não tenham explicitamente tais comportamentos, não tomam nenhuma atitude efetiva no sentido de impedir as discriminações por parte dos outros alunos. Logo, acabam sendo cúmplices do escárnio e da violência para com homossexuais ou para com aqueles que têm um comportamento não exatamente igual ao que a sociedade estabeleceu como masculino.

Entre os entrevistados, os posicionamentos a respeito da Educação Física e da figura do professor no tratamento para com os homossexuais nos demonstrou um quadro alarmante. A Educação Física foi considerada uma das disciplinas mais discriminadoras do espaço escolar:

era como se eu não existisse (...) como eu não era o que jogava bem (...) o que corria bem, (...) na Educação Física, era como se eu não existisse, eu era mais uma peça que estava ali, que tinha se encaixado num time ou numa brincadeira. (Entrevista 5).

Na verdade, o professor de Educação Física foi apontado entre os grandes responsáveis por esse processo discriminatório e preconceituoso. Seja na escola...

$\mathrm{Eu}$ fiquei isento, sabia? O professor me isentou (...) eu não fíz Educação Física. Eu era o "rosinha", eu era o "mariquinha" (...)Ele me

... o estereótipo
acerca das
brincadeiras não
se justifica e o
que se apresenta
é um quadro
muito mais
complexo. Não é
o homossexual
que não gosta de
praticar as
atividades, mas
existem uma
série de fatores
que o impede, o
afasta das
atividades.

atividades. 
prejudicou em outras aulas, em outras matérias...porque ao levar para os meninos que eu era a "rosinha", que eu não ia agüentar aquela bola de dois quilos, de três quilos..., os meninos levavam isso aí para a sala de aula (...) eu queria ter ouvido o que os outros meninos ouviam, eu não queria a discriminação, eu queria ser eu, eu queria praticar a aula, queria fazer todos os exercícios, nunca me recusei a fazer qualquer coisa (...) eu fui tolhido disso. Me tiraram o direito de fazer isso. Quem dita as normas na escola é o professor e a gente tem que cumprilas. (Entrevista 1).

\section{ou seja fora da escola...}

...cheguei a ir para academias. E não mudou nada, a coisa era a mesma ... porque se ele me ver homossexual ele vai fazer comigo o que ele faz com os outros, que ele próprio picha comigo não sabendo que eu sou... O que acontece? Você sai da academia, porque você perde espaço... você não está sendo você, não está sendo autêntico ali dentro. Isso acontece na academia também. (Entrevista 6).

Os entrevistados apontaram também que a Educação Física escolar e o professor foram um dos principais responsáveis para o seu futuro afastamento das atividades físicas/ esportivas fora da escola:

O professor tem uma grande parcela de culpa aí nessa história (...) Eu gosto dessa coisa do esporte, eu curto essa coisa do esporte. Mas com certeza frustrado (...), porque você não me vê jogando um vôlei na beira da praia... (Entrevista 1)

Apesar do afastamento da maioria dos homossexuais entrevistados das atividades físicas/esportivas, alguns ainda tiveram experiências na área, invariavelmente sendo vítimas de preconceitos e discriminações. Na verdade, o espaço para sua prática

...é bem fechado...se eu quiser ir remar, ser um atleta do remo e assumidamente gay, não vai dar certo(...) ou eu vou ter que me camuflar, me esconder, para ser um atleta do remo, que faz, que treina com os outros heteros, para ser um desportista, ou eu não vou poder fazer remo. (Entrevista 2).

Aos entrevistados que ainda hoje praticam essas atividades, só acabam restando os espaços exclusivamente freqüentados por homossexuais e/ou simpatizantes.

...Vôlei, eu tenho que ir lá para a "bolsa", a praia gay $^{10}$. Ou tenho um grupo de amigos, que a gente chama de simpatizante, que me abram a guarda para eu poder jogar uma partida. Fora isso você não joga nunca. (Entrevista 1)
Isso, no entanto, não é visto como uma solução para o problema. Os entrevistados apontaram que o ideal seria que eles pudessem praticar sua atividade em qualquer local, independentemente de opção sexual. Eventos como as "Olimpíadas Gays" foram citados como importantes, já que abrem espaço para os homossexuais e podem conscientizar as pessoas no sentido de atenuar o preconceito e a discriminação, mas também são eles próprios preconceituosos e discriminadores.

...é uma coisa interessante porque você mostra para o mundo que o gay é uma pessoa normal, a única diferença é que gosta de fazer amor com pessoas do mesmo sexo. (Entrevista 7)

...eu acho que é uma discriminação também. Porque não tinha que ter olimpíadas gays, tinha que ter olimpíadas e os gays poderiam participar das olimpíadas. Independente de opção, de determinação sexual. (Entrevista 5)

Esses comportamentos homofóbicos acabam por relegar aos homossexuais um plano diferenciado, que os fazem esconder seus sentimentos e sua forma de ser, já que temem os diversos tipos de agressão. Temem também que sua carreira esportiva (para os atletas de alto nível) ou sua participação nas brincadeiras do grupo sejam prejudicadas. Muitos são mesmo levados a apresentarem "credenciais heterossexuais", como uma relação forjada ou não desejada com indivíduo do sexo oposto.

Zé Roberto (1986), famoso jogador do futebol carioca na década de 70, ao comentar sua vida no futebol profissional, afirma:

No futebol, posso garantir a vocês, homossexual não sobrevive jogando. Pode até existir, mas ideologicamente, sem raspar a perna ou cruzála, delicadamente, para apoiar o cotovelo enquanto conversa (p.42).

$\mathrm{O}$ autor continua abordando a questão referendando um exemplo que várias vezes é utilizado para justificar o afastamento de homossexuais da prática esportiva:

Tampouco o ambiente carregado de indelicadezas permitiria que alguém, sem fazer alarde ou despertar suspeitas, desfilasse nu pelas duchas de um vestiário sem deslizar por delicadas atitudes, (ibid, p.43).

É interessante observar os estereótipos por trás das considerações do autor. O homossexual é sempre visto como um delicado, in- 
capaz de ter uma atitude normal e respeitável. Além disso, subliminarmente, existe uma concepção de que estaria sempre pronto a bolinar os atletas nus, tal como se fosse um tarado insaciável. Zé Roberto ainda ratifica mais as observações anteriores:

Há inclusive uma patrulha fisiológica...: o jogador que passa dos 30 e ainda não casou, começa a ser alvo de gracinhas do grupo, que encara o matrimônio como uma irrefutável prova de comprometida virilidade. (ibid, p.43)

Dificuldades dessa natureza também são sentidas por professores (e professoras) homossexuais, fadados a esconder sua homossexualidade, já que são um "péssimo exemplo" para as crianças, não possuem "postura moral adequada" ou até mesmo podem ser acusados de utilizar sua situação para recrutar jovens e crianças para suas práticas sexuais, um mito bastante presente em torno da figura do homossexual. Tem assim que se esconder, se desejarem manter o emprego (Lenskyj, op.cit.).

$\mathrm{Na}$ verdade, segundo Anne Flintoff (1994), a discriminação na Educação Física e no esporte é construída em cima de uma imagem estereotipada que reforça a identidade masculina dessas práticas culturais. Logo, a homossexualidade e a feminilidade são utilizadas como referências negativas.

Lenskyj (op.cit.) referenda essa posição ao perceber que o grande desafio das mulheres no esporte é ocupar um espaço legitimado enquanto um espaço masculino. Na verdade, elas não são aceitas como mulheres, mas sim como "homens honorários". A autora percebe, inclusive, como as próprias pesquisas no campo do esporte reforçam os preconceitos homofóbicos.

Enfim, o preconceito e a discriminação foram fartamente identificados nos depoimentos de nossos entrevistados, referendando algumas posições e constatações de estudos internacionais. Queremos, no entanto, adendar uma reflexão que, a nosso ver, torna o problema mais grave na realidade nacional. Ao compararmos o Brasil com outros países, principalmente os Estados Unidos, veremos que o preconceito e a discriminação parecem ser maiores, fruto da constituição cultural de nossa sociedade, da recência de discussões dessa natureza e da menor existência de grupos organizados de homossexuais. Possivelmente os impedimentos para a prática de atividades físicas/ esportivas ainda devem ser maiores no Brasil.

Deve-se ressaltar que, embora tenham aumentado muito as preocupações com as classes mistas, com a coeducação e com as relações de gênero no contexto da prática de atividades físicas/esportivas, as preocupações no que se refere aos preconceitos e discriminações para com homossexuais ainda não são fartamente observáveis, principalmente no Brasil. Estas questões devem constituir-se em um grande desafio para os professores de Educação Física. Não pode existir uma preocupação social legítima sem que se considere os homossexuais enquanto indivíduos que merecem ter uma prática de atividades físicas/esportivas não discriminatória e não isolada dos heterossexuais. Os professores não podem mais deixar de considerar esses indivíduos como merecedores de sua atenção.

M. Talbot (1990) sugere que três estágios devem ser considerados na abordagem do assunto. Primeiro, o assunto deve tornar-se visível. Segundo, deve ser legitimado e visto como um assunto importante e significativo. Por fim, os apontamentos devem resultar em uma ação objetiva. Não é nosso objetivo neste texto encerrar as discussões em torno do assunto. Mas, com os resultados de nossa pesquisa, esperamos colocá-lo nas pautas de discussões (torná-lo visível); esperamos estar dando os primeiros passos no sentido de tornálo reconhecido como importante (legitimá-lo) e, pretensiosamente, dar alguns indicadores iniciais para os profissionais em seus campos de atuação (contribuir objetivamente para a atuação).

Gostaríamos de concluir com uma citação de um dos entrevistados, que bem pode resumir todo o sentido deste estudo.

Porque eu não era nada daquilo que eles me chamavam. Eu não era "rosinha", eu não era "mariquinha", eu apenas era eu. E era tudo que eu queria dentro da Educação Física, dentro da prática do esporte, era ser eu. Não sei por que eu não consigo estourar a bola em cima com um cara cortando, não sei, enfim, não sei o que me 
$f a z$ ser menos homem do que vocês. Eu sou tão homem quanto vocês, para qualquer outra atividade. Só tem um jeito diferente, gostar de outro homem, só isso, mas sou tão homem quanto qualquer outro. Não tenho deficiência nenhuma, nem dificuldade em ser pessoa. (Entrevista 1)

\section{REFERÊNCIAS BIBLIOGRÁFICAS}

DELEUZE, Gilles; GUATTARI, Félix. L'Anti Oedipe. Paris: Editions de Minut, 1972.

DERRIDA, Jacques. L'ecriture et la difference. Paris: Editions de Minut, 1967.

FLINTOFF, Anne. Sexism and homophobia in physical education: the challenge for teacher educators. Physical Education Review, vol. 17, n.2, 1994, p.97-105.

FRY, Peter; MacRAE, Edward. O que é homossexualidade. São Paulo: Brasiliense, 1991.

LEONARD, W. Blacks in Sports. In: WIDMEYER, W. Neil. Physical Activity and the Social Sciences. Woodstock: Mouvement Publications, 1983.

LENSKYJ, Helen. Combating homophobia in sport and physical education. Sociology of Sport Journal, n.8, 1991, p.61-69.

LORDE, A. Sister outside. Nova Iorque: Crossing Press, 1984.

LYOTARD, Jean François. La Condition PostModerne. Paris: Editions de Minut, 1979.

MARINHO, Inezil Penna. Sistemas e métodos de educação física. Rio de Janeiro: [s.n.], 1953.

ROBERTO, Zé. Futebol: A dor de uma paixão. Rio de Janeiro: Editora Núcleo-3, 1986.

ROUANET, Sérgio Paulo. As razões do iluminismo. São Paulo: Companhia das letras, 1987.

SOARES, Carmem Lúcia. Educação física: raízes européias e Brasil. Campinas: Autores Associados, 1994.

TALBOT, M. Equal opportunities and physical education. In: ARMSTRONG, N. News directions in physical education. Leed: Human Kinetics, 1990.

\section{NOTAS}

${ }^{1}$ Adotamos o conceito norte-americano 'GLS' que designa e agrupa gays, lésbicas e heterossexuais simpatizantes do movimento.
${ }^{2}$ Neste estudo, os campos de atuação dos professo res da área são simplificadamente apresentados em escolar (ginástica, jogo, dança e esporte no âmbito da escola) e não-escolar (as mesmas atividades no âmbito dos clubes, academias e na prática comuni tária, em geral).

${ }^{3}$ Em futuros estudos estaremos abordando os pre conceitos e discriminações para com lésbicas.

${ }^{4}$ Neste estudo, estamos definindo preconceito como sentimento ou atitude desfavorável a uma pessoa e/ou grupo. Já discriminação é definida como um tratamento desfavorável a uma pessoa e/ou grupo (Leonard, 1983).

${ }^{5}$ A saúde é entendida aqui em seu conceito reduzi do como ausência de doenças.

${ }^{6}$ Helen Lenskyj (1991), por exemplo, afirma que pelo menos quatro organizações no Canadá e nos Estados Unidos têm demonstrado grande interesse pelo assunto: Women's Sports Foundation (desde 1983); Canadian Association for the Advancement of Women and Sport (desde 1985); American Alliance for Health, Physical Education and Recreation (desde 1987); e Canadian Association for Health, Physical Education and Recreation (des de 1988).

${ }^{7}$ Não adotaremos qualquer forma de identificação dos entrevistados em respeito a solicitação dos mesmos.

${ }^{8}$ Peter Fry e Edward MacRae (op.cii) afirmam que desde a mais tenra idade os homens são preparados para serem "...fortes, trabalhadores capazes de sustentar sua família, interessados em futebol e outras atividades definidas como masculinas e, sobretudo, não deveriam chorar" (p.41).

${ }^{9}$ Não são incomuns frases do tipo "tente jogar como homem", "deixa de frescura, parece uma mulherzinha" ou "nem parece um homem jogando, assim você parece uma frutinha".

${ }^{10}$ A "bolsa" é uma parte da praia de Copacabana freqüentada por grande número de homossexuais. Devido a essa freqüência, os homossexuais têm mais liberdade para se comportarem de acordo com seus hábitos e vontades.

\section{UNITERMOS}

Homossexualismo - Preconceito - Discriminação.

*Mestrado em Educação - Univ.do Estado do Rio de Janeiro/Colégio Pedro II

**Doutorado em Educação Física - Univ. Gama Filho/Universidade Federal Fluminense 